\title{
Evaluation of the ovarian reserve after fertility-sparing surgery for ovarian malignancy by measuring the level of serum anti-Müllerian hormone
}

\author{
Akiko Kawasaki*, Ayumi Shikama, Nobutaka Tasaka, Azusa Akiyama, Manabu Sakurai, Hiroyuki Ochi, Takeo Minaguchi and Toyomi \\ Satoh \\ Department of Obstetrics and Gynecology, Faculty of Medicine, University of Tsukuba, Tennoudai 1-1-1, Tsukuba, Ibaraki, 305-8575, Japan
}

\begin{abstract}
Purpose: To investigate whether the level of serum anti-Müllerian hormone (AMH) can be used to evaluate ovarian reserve in patients who underwent fertilitysparing surgery (FSS) for ovarian malignancies.

Methods: We measured the levels of serum AMH and follicle stimulating hormone preoperatively and one month postoperatively. Eighteen patients were recruited; five were excluded from the analysis because their final diagnoses were benign tumors. Of the remaining 13 patients, three had malignant ovarian tumors and 10 had borderline ovarian tumors.

Results: The mean pre-operative and post-operative levels of serum AMH after excluding patients with granulosa cell tumors were $2.85 \mathrm{and} 1.75 \mathrm{ng} / \mathrm{ml}$, respectively. The postoperative AMH levels were significantly lower. The average decrease in $\mathrm{AMH}$ was $38.6 \%$. Aging and the stages of the disease were related to severe decreases in the AMH levels.
\end{abstract}

Conclusion: Measuring serum AMH level is useful in evaluating the ovarian reserve in patients with ovarian malignancies after FSS.

Abbreviations: FSS: fertility-sparing surgery, AMH: Anti-Müllerian hormone, FSH: Follicle-stimulating hormone.

\section{Introduction}

With the advancements in cancer treatment, the prognoses of cancers in young patients have improved remarkably. Female cancer survivors with delayed marriage and childbirth require the use of assisted reproductive techniques. These techniques are also required in patients with ovarian malignancies.

The standard surgery for malignant ovarian tumors usually includes total resection of the uterus and both ovaries. According to the guidelines of the Japanese Society of Obstetrics and Gynecology, preservation of a part of the uterus and ovaries is permitted for some subgroups of patients with good prognoses, which include patients with early stage high-grade epithelial ovarian cancers, borderline ovarian tumors, and malignant germ cell tumors [1]. Some studies have reported that fertility-sparing surgery (FSS) can be extended to malignant ovarian tumors [2,3]. Currently, a Japanese clinical oncology group is performing a prospective non-randomized verification study regarding the selection of patients with epithelial ovarian cancer for FSS [4].

Anti-Müllerian hormone (AMH) is a dimeric glycoprotein that belongs to the transforming growth factor- $\beta$ superfamily. It is produced by the Sertoli cells in the genitalia of male fetuses and plays a role in the regression of the Müllerian ducts. In women, AMH is mainly secreted by granulosa cells of small follicles, and it inhibits the growth of the resting primordial follicles $[5,6]$. In reproductive medicine, serum
AMH level is used as a marker of ovarian reserve because it correlates with the number of resting primordial follicles. It decreases due to aging and other external factors, such as ovarian surgery, chemotherapy, and radiation [7-10].

In this study, we used the level of serum AMH as a marker of ovarian reserve. The purposes of this study were to investigate whether the ovarian reserve can be evaluated by measuring the level of serum $\mathrm{AMH}$ and identify the factors that are related to the alteration of the ovarian reserve in FSS for ovarian malignancies.

\section{Methods}

Eighteen patients with malignant ovarian tumors or borderline ovarian tumors who underwent FSS at the University of Tsukuba Hospital between August 2014 and March 2017 were included. We grouped malignant ovarian tumors and borderline ovarian tumors into ovarian malignancies. The preoperative diagnosis of ovarian malignancies was based on computed tomography or magnetic resonance images and tumor markers. Alternatively, it was based on

*Correspondence to: Akiko Kawasaki, Department of Obstetrics and Gynecology, Faculty of Medicine, University of Tsukuba, Tennoudai 1-1-1, Tsukuba, Ibaraki, 305-8575, Japan, Tel +81-29-853-3073; Fax +81-29-853-3072; E-mail: akawasaki@md.tsukuba.ac.jp

Key words: anti-Müllerian hormone, fertility preservation, malignant ovarian tumor, ovarian reserve, fertility-sparing surgery

Received: August 17, 2018; Accepted: August 28, 2018; Published: August 31, 2018 
the pathological diagnosis during the first surgery performed for the estimation of benign tumors. In the latter cases, FSS was performed as an additional surgery. Patients who were either older than 45 years of age or post-menopausal were excluded. Of the 18 patients, five were excluded from the analysis because the pathological diagnoses were later found to be benign tumors.

The clinicians explained the disease and treatments to the patients, and preoperative blood sampling was performed. Blood sampling was also performed a month after the surgery.

AMH concentrations were measured with a Gen II enzyme immunoassay (Beckman Coulter Inc., Sacramento, CA, USA) between August 2014 and March 2016, and with Gen II chemiluminescence assay (CLIA) (Beckman Coulter Inc., Sacramento, CA, USA) between April 2016 and March 2017. The correlation equation was $\mathrm{Y}=0.847 \mathrm{X}+0.258$ $(\mathrm{R}=0.985)$ between the two assays. Follicle-stimulating hormone (FSH) concentration was measured using the $\mathrm{E}$ test TOSOH II (FSH) (Toso Inc., Tokyo, Japan).

The statistical analyses were performed using the Statistical Solutions for the Social Sciences (SPSS) software, version 21.0 for Windows. A paired t test and Wilcoxon's signed-rank test were used for evaluating the pre- and post-surgery serum AMH and FSH levels. An unpaired $t$ test or Mann-Whitney's $U$ test was used for continuous variables, and a Chi-squared test was used for categorical variables in the analysis of factors related to a decrease in the serum AMH levels. A $P$-value $<0.05$ was considered statistically significant.

\section{Results}

The patients' ages ranged between 16 and 44 years (mean \pm standard deviation: $30 \pm 8.8$ years). The baseline characteristics of the patients are shown in Table 1 . The average AMH levels in these patients, excluding those with granulosa cell tumors, decreased significantly between preoperative $(2.85 \pm 1.57 \mathrm{ng} / \mathrm{ml})$ and postoperative assessments $(1.75$ $\pm 1.01 \mathrm{ng} / \mathrm{ml})$. The average AMH values of these patients, excluding those with granulosa cell tumors and those who underwent the second surgery, also decreased significantly between pre-surgery $(3.15 \pm 1.58$ $\mathrm{ng} / \mathrm{ml})$ and post-surgery assessments $(1.97 \pm 0.97 \mathrm{ng} / \mathrm{ml})$. The average AMH values, including those of patients with granulosa cell tumors, decreased remarkably between pre-surgery $(34.22 \pm 108.90 \mathrm{ng} / \mathrm{ml})$ and post-surgery assessments $(1.57 \pm 1.01 \mathrm{ng} / \mathrm{ml})$; however, there was no significant difference. In one case (patient No. 16), an increase in AMH value postoperatively was observed.

Postoperatively, serum FSH values increased significantly in patients with granulosa cell tumors and those without (from $7.13 \pm$ 1.77 to $9.03 \pm 4.14 \mathrm{IU} / \mathrm{ml}$, and from $7.05 \pm 1.83$ to $9.76 \pm 3.80 \mathrm{IU} / \mathrm{ml}$, respectively). In patients without a granulosa cell tumor or those who underwent the second surgery, the value increased postoperatively, without a significant difference (from $7.20 \pm 1.82$ to $9.96 \pm 4.20 \mathrm{IU} /$ $\mathrm{ml})$. In patients without a granulosa cell tumor, the average change in the AMH levels postoperatively was $38.60 \%$. In patients without a granulosa cell tumor and who did not undergo the second surgery, the average change in the AMH postoperatively was $37.46 \%$.

The median values of AMH and FSH pre- and post-surgery are shown in Figure 1. In patients without a granulosa cell tumor, the median AMH decreased significantly between the pre-surgery $(2.34$ $\mathrm{ng} / \mathrm{ml}$ [range: 1.50-3.68]) and post-surgery assessments $(1.72 \mathrm{ng} / \mathrm{ml}$ [range: $0.81-2.58$ ]). In patients without a granulosa cell tumor and who did not undergo the second surgery, the median AMH also decreased significantly between the pre-surgery and post-surgery assessments $(2.74 \mathrm{ng} / \mathrm{ml}$; range: 1.64 to 3.87 to $1.99 \mathrm{ng} / \mathrm{ml}$, range: 0.97 to 2.88 ).
Table 1. The baseline characteristics of patients with ovarian malignancies

\begin{tabular}{|l|c|}
\hline Characteristic & Value \\
\hline Age (years) & $30.15 \pm 8.76$ \\
\hline Diameter of tumor (mm) & $160.23 \pm 113.73$ \\
\hline & \\
\hline The type of surgery & 13 \\
\hline Unilateral adnexectomy & 8 \\
\hline add. partial omentectomy & 6 \\
\hline add. lymph node resection & 2 \\
\hline add. opposite ovarian biopsy & $98.05 \pm 33.67$ \\
\hline & \\
\hline Operation time (min) & $52.15 \pm 60.16$ \\
\hline & \\
\hline Bleeding (g) & 5 \\
\hline & \\
\hline Ovarian malignant tumor & 10 \\
\hline Low potential malignancy & 3 \\
\hline & \\
\hline Epithelial ovarian tumor & 6 \\
\hline Germ cell tumor & 7 \\
\hline & \\
\hline Stage IA & \\
\hline More & \\
\hline
\end{tabular}

Numerical data are reported as average \pm standard deviation. Categorical data are reported as numbers.
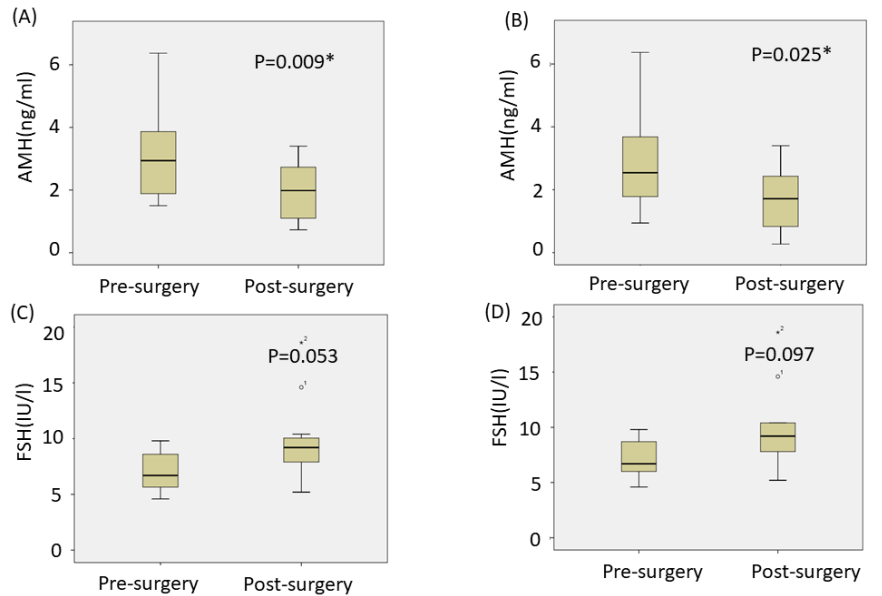

Figure 1. Comparison of the median pre- and postoperative AMH levels except patients with a granulosa cell tumor (A), and in all patients, except for those with a granulosa cell tumor and who underwent the second surgery (B). Comparison of the median pre- and postoperative FSH levels, except patients with a granulosa cell tumor (C), and in all patients except for those with a granulosa cell tumor and who underwent the second surgery (D). The median AMH decreased significantly between the pre-surgery and post-surgery in (A) and (B). The medians and interquartile ranges are shown. ${ }^{*} \mathrm{P}<0.05$

However, there was no significant difference between the median FSH levels preoperatively and postoperatively.

We analyzed the factors related to an extreme decrease in $\mathrm{AMH}$ (ED-AMH) postoperatively (Table 2). ED-AMH was defined as cases with a fall in serum $\mathrm{AMH}$ to less than $1 \mathrm{ng} / \mathrm{ml}$ postoperatively. Non$\mathrm{ED}-\mathrm{AMH}$ was defined as cases in which the serum AMH decreased to $1 \mathrm{ng} / \mathrm{ml}$ or more postoperatively. Several hypothetical factors that were related to ED-AMH and non-ED-AMH were evaluated. Significant differences were observed in the age and stage of cancer between the two groups (age: $24.43 \pm 6.66$ vs. $36.83 \pm 5.64, P=0.004$; staging: IA vs. IC or greater, $P=0.048)$. 
Table 2. Factors that are related to a severe decrease in AMH postoperatively

\begin{tabular}{|l|c|c|c|}
\hline & non ED-AMH & ED-AMH & p value \\
\hline Age (years) & $24.43 \pm 6.66$ & $36.83 \pm 5.64$ & $0.004^{*}$ \\
\hline Preoperative AMH (ng/ml) & $3.27 \pm 1.66$ & $64.68 \pm 154.48$ & 0.375 \\
\hline Operation time (min) & $91.57 \pm 20.44$ & $105.83 \pm 45.70$ & 0.504 \\
\hline & & & \\
\hline Bleeding (g) & $61.43 \pm 72.58$ & $41.33 \pm 45.87$ & 0.571 \\
\hline & & & \\
\hline Maximum diameter (mm) & $178.00 \pm 120.99$ & $139.50 \pm 111.87$ & 0.566 \\
\hline & & & \\
\hline Ovarian malignant tumor & 3 & 2 & 0.725 \\
\hline Low potential malignancy & 4 & 4 & \\
\hline & & & \\
\hline Epithelial ovarian tumor & 6 & & \\
\hline Germ cell tumor & 1 & 5 & \\
\hline
\end{tabular}

AMH: anti-Müllerian hormone; ED-AMH: extreme decrease in $\mathrm{AMH} * \mathrm{P}<0.05$

\section{Discussion}

This is the first report to prove that a decrease in ovarian reserve can be evaluated by measuring the AMH levels before and after FSS for ovarian malignancies.

The lack of a significant decrease in the levels of AMH after ovarian FSS in all patients, including those with a granulosa cell tumor, is presumably because it was extremely high in one patient with a granulosa cell tumor. In such cases, $\mathrm{AMH}$ is produced by the granulosa cell tumor [11]. Because the division of data values was enlarged, a statistical error is likely.

We analyzed the patients and excluded those who underwent the second surgery because the physiological statuses of these patients are different from that of other patients in whom almost all tumor components were already resected. In patients who did not undergo the second surgery, the AMH levels also significantly decreased postoperatively, indicating that our results are reliable.

Serum FSH level is an established marker of ovarian reserve. The average FSH and the median FSH in patients without granulosa cell tumors and the second surgery did not significantly change between the pre- and post-surgical assessments. One reason for the inferior sensitivity of FSH compared to that of AMH might be that the serum FSH remarkably fluctuates during menstrual cycles while the fluctuation of serum AMH is insignificant [12].

Malignant tumors should be treated immediately after diagnosis; therefore, the measurement of serum AMH is considered a more appropriate tool than that of serum FSH.

According to previous reports, the distribution of the change in serum AMH levels between pre- and post-surgical assessments ranged between 14 and 55\% [13-23]. Lee et al. [16] found that the serum AMH level decreased by $51 \%$ after unilateral adnexectomy in ovarian endometriomas. Therefore, the rate of $37-39 \%$ that was shown in this study after surgery for ovarian malignancies is not as high as that in surgeries for benign ovarian tumors, even though some patients underwent unilateral adnexectomy with biopsy of the opposite ovary. The post-surgical decrease in $\mathrm{AMH}$ in patients with malignant ovarian tumors is suggested to be less severe than that in patients with a benign tumor. In previous studies, patients with a malignant tumor tended to have a relatively low ovarian reserve $[24,25]$.

Resecting the malignant tumors in these patients can presumably improve the ovarian reserve. However, we should be careful while analyzing the results of previous studies because they included cases of resection of endometrioma. Resection of endometrioma decreases the ovarian reserve more severely than resection of other types of benign ovarian tumors does $[13,15,22,26]$. The small decrease in AMH shown in this study presumably is because this study did not include patients with endometrioma.

The results of this study suggest that a severe decrease in the AMH values postoperatively is related to the age of the patient. The ability of older patients to recover from operative stress is diminished. Similar to this study, Celik et al.'s [19] study reported that patients with reduced ovarian reserve preoperatively are likely to suffer from a severe decrease in the serum AMH postoperatively. Iwase et al. [27] reported that the risk of a severe decrease in $\mathrm{AMH}$ is higher in patients who are older than 40 years of age than in younger patients after FSS for malignant ovarian tumors. We suggest that when FSS is performed for ovarian malignancies in women of older reproductive age, the surgeons should consider that the surgery could be harmful to the ovarian reserve.

Patients whose cancer is classified as greater than stage IA have a more severe decrease in serum AMH levels than those whose cancer is classified as stage IA. According to studies demonstrating the relationship of tumor diameter with the rate of decline in AMH levels after surgery, patients with larger tumors demonstrated more severe decreases in AMH levels than patients with smaller tumors did [14,28]. A more advanced disease is possibly related to decreases in the normal ovarian cortex resulting in the remarkable damage to the ovarian reserve.

Khan et al. [28] reported that the remaining ovary compensates for follicular yield after unilateral oophorectomy during ovarian stimulation. Ovarian compensation is supposed to occur due to an increase in the sensitivity to gonadotropin in the remaining ovarian tissue. According to one hypothesis, a decrease in the level of AMH due to ovarian resection causes compensation of the ovarian reserve, because AMH is an inhibitory factor to the recruitment of primordial follicles [5].

The diverse patterns of changes in the AMH levels after surgery possibly reflect the diverse compensation potential of the residual ovary. According to studies that evaluated AMH for 1 year postoperatively, its levels were recovered in certain patients after 3 months $[15,16,19,20,21]$. The limitation of this study is that the post-surgery serum AMH was measured within a month after the surgery and the recovery of the ovarian reserve over the long term was not investigated.

In classical studies, the outcomes of FSS were evaluated using the maintenance of menstrual cycles and pregnancy rate $[29,30]$. However, ovarian reserve is an important issue in fertility and success in reproductive medicine. Clinicians should be attentive to not only protecting the lives of patients, but also to maintain their fertility and ovarian reserve.

Changes in serum AMH levels postoperatively are useful to evaluate the ovarian damage in patients with malignant ovarian tumors who undergo FSS. Aging and the stages of the disease are possibly related to severe decreases in the AMH levels. 
The limitation of this study is that the sample size was too small to conclude the results. Thus, further large study will be needed to clarify these relations.

\section{Disclosures}

The authors report no conflicts of interest. This study was approved by the Institutional Review Board of University of Tsukuba Hospital. Written informed consent was obtained from each patient.

\section{References}

1. Japan Society of Gynecologic Oncology. [Ovarian Cancer Treatment Guidelines] Tokyo, Japan: Kanehara; 2015. Japanese.

2. Satoh T, Hatae M, Watanabe Y, Yaegashi N, Ishiko O, et al. (2010) Outcomes of fertility-sparing surgery for stage I epithelial ovarian cancer: a proposal for patient selection. J Clin Oncol 28: 1727-1732. [Crossref]

3. Bentivegna E, Fruscio R, Roussin S, Ceppi L, Satoh T, et al. (2015) Long-term followup of patients with an isolated ovarian recurrence after conservative treatment of epithelial ovarian cancer: review of the results of an international multicenter study comprising 545 patients. Fertil Steril. 104: 1319-1324. [Crossref ]

4. Satoh T, Tsuda H, Kanato K, Nakamura K, Shibata T, et al. (2015) A non-randomized confirmatory study regarding selection of fertility-sparing surgery for patients with epithelial ovarian cancer: Japan Clinical Oncology Group Study (JCOG 1203). Jpn J Clin Oncol. 45: 595-599.

5. Grynnerup AG, Lindhard A, Sørensen S (2012) The role of anti-Müllerian hormone in female fertility and infertility - an overview. Acta Obstet Gynecol Scand 91: 12521260. [Crossref]

6. Broer SL, Broekmans FJM, Laven JS, Fauser BCJM (2014) Anti-Müllerian hormone: ovarian reserve testing and its potential clinical implications. Hum Reprod Update. 20: 688-701. [Crossref]

7. Almog B, Shehata F, Suissa S, Holzer H, Shalom-Paz E, et al. (2011) Age-related normograms of serum antimüllerian hormone level in a population of infertile women: a multicenter study. Fertil Steril. 95: 2359-2363. [Crossref]

8. Legendre G, Catala L, Morinière C, Lacoeuille C, Boussion F, et al. (2014) Relationship between ovarian cysts and infertility: what surgery and when? Fertil Steril 101: 608614. [Crossref]

9. Anderson RA, Wallace WH. (2013) Antimüllerian hormone, the assessment of the ovarian reserve, and the reproductive outcome of the young patient with cancer. Fertil Steril. 99: 1469-1475. [Crossref ]

10. Iwase A, Nakamura T, Osuka S, Takikawa S, et al. (2015) Anti-Müllerian hormone as a marker of ovarian reserve: What have we learned, and what should we know? Reprod Med Biol 15: 127-136. [Crossref]

11. Chang HL, Pahlavan N, Halpern EF, MacLaughlin DT (2009) Serum Müllerian Inhibiting Substance/anti-Müllerian hormone levels in patients with adult granulosa cell tumors directly correlate with aggregate tumor mass as determined by pathology or radiology. Gynecol Oncol 114: 57-60. [Crossref ]

12. Kissell KA, Danaher MR, Schisterman EF, Wactawski-Wende J, Ahrens KA, et al. (2014) Biological variability in serum anti-Müllerian hormone throughout the menstrual cycle in ovulatory and sporadic anovulatory cycles in eumenorrheic women. Hum Reprod. 29: 1764-1772. [Crossref]

13. Iwase A, Hirokawa H, Goto M, Takikawa S, Nagatomo Y, et al. (2010) Serum antiMüllerian hormone level is a useful marker for evaluating the impact of laparoscopic cystectomy on ovarian reserve. Fertil Steril. 94: 2846-2849. [Crossref ]
14. Ercan CM, Sakinci M, Duru NK, Alambay I, Karasahin KE, et al. (2010) Antimullerian hormone levels after laparoscopic endometrioma spripping surgery. Gynecol Endocrin. 26: 468-472. [Crossref]

15. Chang HJ, Han SH, Lee JR, Lee BC, Lee BI, et al. (2010) Impact of laparoscopic cystectomy on ovarian reserve: serial changes of serum anti-Müllerian hormone levels. Fertil Steril. 94: 343-349. [Crossref ]

16. Lee DY, Kim NY, Kim MJ, Yoon BK, Choi D. (2011) Effect of laparoscopic surgery on serum anti-müllerian hormone levels in reproductive-aged women with endometrioma. Gynecol Endocrin. 27: 733-736. [Crossref ]

17. Mohamed ML, Nouh AA, El-Behery MM, Mansour SAEA. (2011) Effect on ovarian reserve of laparoscopic bipolar electrocoagulation versus laparotomic hemostatic sutures during unilateral ovarian cystectomy. Int J Gynaecol Obstet. 114: 69-72. [Crossref]

18. Hirokawa W, Iwase A, Goto M, Takikawa S, Nagatomo Y, et al. (2011) The postoperative decline in serum anti-Mullerian hormone correlates with the bilaterality and severity of endometriosis. Hum Reprod 26: 904-910. [Crossref ]

19. Celik HG, Dogan ED, Okyay E, Ulukus C, Saatli B, et al. (2012) Effect of laparoscopic excision of endometriomas on ovarian reserve: serial changes in the serum antimüllerian hormone levels. Fertil Steril. 97: 1472-1478. [Crossref ]

20. S?nmezer M, Ta?kin S, Gemici A, Kahraman K, Ozme B, et al. (2013) Can ovarian damage be reduced using hemostatic matrix during laparoscopic endometrioma surgery? A prospective, randomized study. Arch Gynecol Obstet. 287: 1251-1257. [Crossref ]

21. Sugita AS, Iwase A, Goto M, Nakahara T, Kondo M, et al. (2013) One-year followup of serum antimüllerian hormone levels in patients with cystectomy: are different sequential changes due to different mechanisms causing damage to the ovarian reserve? Fertil Steril. 100: 516-522. [Crossref]

22. Chen Y, Pei H, Chang Y, Chen M, Wang H, et al. (2014) The impact of endometrioma and laparoscopic cystectomy on ovarian reserve and the exploration of related factors assessed by serum anti-Mullerian hormone: a prospective cohort study. J Ovarian Res. 7:108. [Crossref]

23. Huang BS, Wang PH, Tsai HW, Hsu TF, Yen MS, et al. (2014) Single-port compared with conventional laparoscopic cystectomy for ovarian dermoid cysts. Taiwan J Obstet Gynecol. 53: 523-529. [Crossref]

24. Dunlop CE, Anderson RA. (2015) Use of anti-Müllerian hormone (AMH) measurement before and after cancer treatment in women. Maturitas. 80: 245-250.

25. Naasan M, Hamity C, Rajab H, Ranisavljevic N, Khalid S, et al. (2016) Patients with cancer at the margins of reproductive age had reduced levels of anti-Müllerian hormone compared with patients experiencing infertility. Int J Gynecol Obstet. 133: 226-229. [Crossref]

26. Kitajima M, Dolmans MM, Donnez O, Masuzaki H, Soares M, et al. (2014) Enhanced follicular recruitment and atresia in cortex derived from ovaries with endometriomas. Fertil Steril. 101: 1031-1037. [Crossref ]

27. Iwase A, Sugita A, Hirokawa W, Goto M, Nakahara T, et al. (2013) Anti-Müllerian hormone as a marker of ovarian reserve in patients with ovarians who have undergone fertilitypreserving surgery and chemotherapy. Gynecol Endocrinol. 29: 357-360. [Crossref]

28. Kahan Z, Gada RP, Tabbaa ZM, Laughlin-Tommaso SK, Jensen JR, et al. (2014) Unilateral oophorectomy results in compensatory follicular recruitment in the remaining ovary at time of ovarian stimulation for in vitro fertilization. Fertil Steril. 101: 722-727. [Crossref ]

29. Ditto A, Martinelli F, Lorusso D, Haeusler E, Carcangiu M, et al. (2014) Fertility sparing surgery in early stage epithelial ovarian cancer. J Gynecol Oncol. 25: 320-327.

30. Song T, Choi CH, Park HS, Kim K, Lee YY, et al. (2011) Fertility-sparing surgery for borderline ovarian tumors: oncologic safety and reproductive outcomes. Int $J$ Gynecol Cancer. 21: 640-646. [Crossref]

Copyright: (C2018 Kawasaki A. This is an open-access article distributed under the terms of the Creative Commons Attribution License, which permits unrestricted use, distribution, and reproduction in any medium, provided the original author and source are credited. 